\section{EL RECONOCIMIENTO DE LA NACIÓN EN LA HISTORIA. EL USO ESPACIO-TEMPORAL DE PINTURAS Y MONUMENTOS EN ESPAÑA}

\author{
Carlos Reyero Hermosilla \\ Departamento de Historia del Arte. Facultad de Filosofía y Letras \\ Universidad Autónoma de Madrid \\ Avenida Tomás y Valiente $s / n$, Cantoblanco \\ 28049 Madrid \\ carlos.reyero@uam.es
}

\begin{abstract}
Historical identities use to be understood as a permanent background, where it is always possible to find prominent figures, with a similar meaning, in order to give form to the nation. Nevertheless, time and space are essential elements in the historical speech. Since it is known, history painting and monuments played a great role in Spain during the $19^{\text {th }}$ century. This articles focuses on the circumstances of these artistic activities. History is used in a different ways according to conservative o liberal ideology or the political moment. Even the place and the moment can change or fix his meaning. It is always necessary to remember that painting and sculpture, although they turned to images, are, first of all, objects that emphasize the importance of public art.
\end{abstract}

KEY WORDS: National Identities; National Imaginaries; Cultural History; Historiography and Culture; Art and Politics; Power and Representaion; Spanish $19^{\text {th }}$ Century Art.

¿Qué trama es ésta del será, del es y del fue? ¿Qué río es éste por el cual corre el Ganges? ¿Qué río es éste cuya fuente es inconcebible? ¿Qué río es éste que arrastra mitología y espadas? Jorge Luis Borges, Heráclito

El imaginario visual de los diferentes nacionalismos ha tratado de presentarse como un repertorio figurativo consolidado, donde lo esencial del mito permanece más allá del espacio y el tiempo. En España, gracias a la fortuna iconográfica que determinados motivos alcanzaron, incluso antes de que la Constitución de Cádiz sancionara la existencia de "la nación española", ha sido fácil argumentar que existía una continuidad en su significado. Los estudios
THE RECOGNITION OF THE NATION IN HISTORY. THE SPACE-TIME USE OF PAINTINGS AND MONUMENTS IN SPAIN

RESUMEN: Las identidades históricas suelen entenderse como un repertorio permanente del que siempre es posible extraer personajes, con un siginificado parecido, con objeto de dar forma a la nación. Sin embargo, tiempo y espacio son elementos esenciales en el discurso histórico. Como se sabe, la pintura de historia y los monumentos representaron un gran papel en España durante el siglo XIX. Este artículo se centra en las circunstancias de estas actividades artísticas. La historia se usó de diferentes maneras según la ideología conservadora o liberal o el momento político. Incluso el lugar y el momento pueden cambiar o fijar su significado. Siempre es necesario recordar que la pintura y la escultura, aunque se convierten en imágenes, son, ante todo, objetos que subrayan la importancia del arte público.

PALABRAS CLAVE: Identidades nacionales; imaginarios nacionales; historia cultural; historiografía y cultura; cultura visual; arte y política; poder y representación; arte español del siglo XIX.

sobre la identidad nacional, ante la evidente repetición de determinados episodios y personajes históricos, suelen considerar que tales imágenes terminaron por conformar un discurso coherente, en el que, por encima de todo, se reconoce un elemento esencial: el alma nacional (Reyero 1987; Pérez Vejo, 2001).

La conclusión tiene su lógica, desde luego, pero sólo se detiene en una de las vertientes que conlleva la utilización de imágenes históricas con fines políticos. Si la nación es una construcción intelectual que requiere un proceso, en el que convergen, no siempre con éxito, intereses complejos, la significación de las imágenes, según el uso que en cada circunstancia se hizo de ellas, debió de ser necesariamente 
distinto. Una cosa es la vanidosa pretensión de intemporalidad que promotores y artistas buscaron (y lograron), y otra es la irremediable sumisión al lugar y al momento en el que las obras artísticas se produjeron, dimensiones fundamentales para comprender cualquier hecho histórico (Reyero, 2005b).

Recuperar en las representaciones de asuntos del pasado, ya sean pinturas o esculturas, su razón de ser histórica puede parecer una forma de desmitificación, porque se las devuelve su papel político (Reyero, 2002). Y la circunstancialidad de la política siempre resulta poca cosa ante la intemporalidad del arte. Pero al fin y al cabo las obras de arte no son sólo imágenes, sino, ante todo, objetos que tuvieron una razón de ser y ocuparon -y ocupan- un espacio. No es fácil reducirlos a su virtualidad. Antes de convertirse en emblemas, fueron fabricados para servir a fines terrenales con intereses muy concretos. Es precisamente su circunstancia la que nos revela los instrumentos visuales del nacionalismo. La utilización de una misma imagen en distintos momentos y lugares no significa perseguir los mismos fines.

La historia desempeñó un papel identitario fundamental en la construcción de la nación a lo largo del siglo XIX. No es que después dejara de tenerlo, incluso con iconos configurados entonces, como prueban billetes, sellos, etiquetas, ilustraciones de manuales escolares o escenas cinematográficas, incluso hasta nuestros dias, aunque se haya visto desplazado su papel frente a otros que, a la postre, han resultado tanto o más importantes, como tipos, paisajes, costumbres, caracteres o monumentos. Pero hay, sobre todo, una diferencia fundamental, a veces no tenida en cuenta: historia y creatividad, al servicio de unos ideales públicos, caminaron juntas hasta que pintura y escultura dejaron en segundo plano la idea de representación que propició su autonomía. La pintura de historia y la escultura conmemorativa son las grandes manifestaciones públicas del arte en el siglo XIX. Esa confluencia de intelectuales, políticos y artistas en la Historia ya no volvió a repetirse.

\section{LA TRADICIÓN ILUSTRADA Y EL USO INSTITUCIONAL DE LA HISTORIA}

El nacionalismo es, como se sabe, fruto del pensamiento político liberal. Pero no debe pensarse que la utilización de la historia como modelo social apareció repentinamente con la nueva ideología política. Personajes y asuntos históricos ya formaban parte del discurso artístico-político español del siglo XVIII. La historia servía no sólo para enraizar a la monarquía en una tradición sobre la que se fundamentaba sino también para modernizarla, en tanto que referente benéfico del gobierno de un pueblo, aunque no puede negarse que esos mismos o parecidos recursos no sirvieran enseguida para ilustrar el nacionalismo, porque, al fin y al cabo, la adhesión a la monarquía constituyó un primer referente de identidad colectiva.

En la Alegoría de la Monarquía Española, pintada por Tiépolo para el Salón del Trono del Palacio Real de Madrid, ya hay referencias al Descubrimiento de América por Colón, y en el comedor de gala, Francisco Bayeu pintó La Rendición de Granada ante los Reyes Católicos y Antonio González Velázquez Cristóbal Colón ante los Reyes Católicos (Checa, 1992, 165-176). Son bien conocidos también los temas de la historia de España que tanto escultores - La rendición de Sevilla a San Fernando, de Andrés Beltrán, o La toma de Toledo, de Humberto Dumandre, por ejemplo- como pintores -Los Reyes Católicos recibiendo a una embajada del rey de Fez, de Vicente López, entre otros- abordaron en la Academia de San Fernando de Madrid a lo largo del siglo XVIII.

La política monumental que se inicia en los primeros años del siglo XIX tuvo en cuenta enseguida a personajes históricos. En 1812 el Ayuntamiento de Madrid, por ejemplo, propuso colocar en la Plaza del teatro del Príncipe una fuente dedicada a Carlos $V$ y en la plaza del Pescado una estatua dedicada a Fernando V obras ambas de Silvestre Pérez, cuyos proyectos se difundieron a través de grabados de Manuel Salvador Carmona. A diferencia de las exaltaciones de los monarcas reinantes, conmemoran dos figuras históricas que honran a la nación, en uno de los primeros testimonios que prueban que el orgullo nacional se nutre de la historia. Poco después, en 1818, se da conocer en la Academia de San Fernando, La muerte de Viriato de José de Madrazo, expuesto en el Prado a partir de 1828, cuyas connotaciones nacionalistas son evidentes; y hacia 1819 Juan Antonio de Ribera pinta Wamba renunciando a la corona para el salón central del Casino de la Reina, en Madrid.

Durante el reinado de Fernando VII $-\mathrm{y}$, en concreto, durante la Ominosa Década, en la que el discurso político sigue 
dominado por la tradicional lealtad al rey, del que se esperan todos los beneficios- hay significativos ejemplos de un uso de la historia, ligado a la Monarquía, desde luego, pero donde se presentan los logros del pasado como una empresa colectiva prolongada hasta el presente. Tengamos en cuenta dos de ellos. Uno, los frescos que Juan Antonio de Ribera pinta en el Palacio del Pardo en 1825, donde aparecen descubridores y conquistadores, escritores y artistas, presididos por la imagen alegórica de España (Miguel Egea, 1985,18-20). Otro, la decoración -no por efímera menos relevante- dispuesta con motivo de la entrada en Madrid de María Cristina de Borbón en 1829 para casarse con Fernando VII, que, en lugar de remitir a la alegoría, como era costumbre, recurre a la historia: asi, en el arco triunfal colocado en la calle de Alcalá había "muchos medallones con la efigie del Rey Alonso el Sabio y de diferentes personajes que se han hecho célebres, así en España como en las Américas. En el ático [...] se distinguían diferentes bajo relieves representando a los Reyes Católicos dando audiencia a Colón"; y en el templete de la Puerta del Sol estaban las estatuas de Cortés, Pizarro, Colón y Elcano (D. M. N. y R., 1829, 12-13). A ellos puede añadirse un tercer ejemplo, promovido a comienzos de 1834, cuando todavía ni siquiera se había promulgado el Estatuto Real: se trata de un proyecto de monumento para conmemorar la jura por las Cortes de Isabel II como heredera del trono. En él estaba previsto un bajorrelieve "en el que se hayan esculpidas las batallas más gloriosas de España y de las cuales dio principio su regeneración". Estas eran las de Covadonga, Clavijo, las Navas de Tolosa "y otras de las más célebres de la Edad Media" (Martín, 1998, 61).

Por lo que se refiere al sistema de enseñanza, durante el primer tercio del siglo XIX, en el seno de la Academia de Bellas Artes de San Fernando de Madrid, cuya importancia como referente de la actividad artística en España es primordial, la práctica en la representación de asuntos de la Historia de España -junto a otros bíblicos o clásicos- se constata en los diversos concursos convocados. Por ejemplo, en 1802, se propuso la defensa de Numancia; en 1805, el recibimiento de Elcano por Carlos V en Valladolid; en 1808, un episodio de las guerras del Gran Capitán; y en 1831, el Descubrimiento del Pacífico por Vasco Núñez de Balboa (Navarrete, 1999, 254-258). Heroicidad y triunfo parecen mensajes asociados a las acciones en las que se veía cómo actuaban los españoles del pasado.

\section{EL IMAGINARIO DEL NACIONALISMO LIBERAL: EL MARTIROLOGIO}

Frente a la idea triunfalista del absolutismo monárquico, en gran parte retomada más adelante por los políticos moderados, los liberales gaditanos, y después los progresistas que se sintieron herederos de aquéllos, recurrieron a la estética victimista como procedimiento de persuasión. Ello no ha de verse como una consecuencia de las dificultades que tuvo por asentarse, acentuadas por las circunstancias de un pueblo involucrado en una guerra que, no por casualidad, acabaría por llamarse de la Independencia, aunque este factor no sea despreciable, sino, más bien, como un aprovechamiento de los recursos del mensaje religioso -el martirio como antesala de la gloria- que en tantos aspectos imitaron. No hay que olvidar que el victimismo constituía una forma de poner en escena un asunto, con objeto de convencer mediante la empatía, que se encuentra en todo el arte del Romanticismo.

Liberalismo y Nacionalismo afloran, pues, en la guerra contra Napoleón, de donde salen los primeros héroes. Los sucesos del Dos de Mayo de 1808 en Madrid, y, en concreto, dos de los soldados caídos, Daoíz y Velarde, proporcionan el primer motivo acogido con encendido entusiasmo por la ideología liberal, como queda constancia en las actas de las Cortes de Cádiz. En Madrid, en el lugar que se acabaría Ilamando Campo de la Lealtad, se levantarian sucesivamente varias construcciones en su memoria, antes de que, en 1840, fuera inaugurado el Obelisco del 2 de Mayo. No obstante, la prevención de la propaganda institucional hacia esa conmemoración, durante las primeras décadas del siglo XIX, es patente. No son muchos los cuadros de historia que antes de 1868 difunden aquellos episodios, los más famosos los de Manuel Castellanos de 1862 y 1864. De hecho, no será hasta el Sexenio Revolucionario cuando sucesos y héroes del Dos de Mayo formen parte de las conmemoraciones patrióticas, al mismo tiempo que pinturas y monumentos empiecen a prodigarse en el espacio público. Es en 1869 cuando se coloca, muy cerca de donde estuvo el Parque de Artillería de Monteléon, que defendieron con arrojo, el grupo de Daoíz y Velarde de Antonio Solá (fig. 1), aunque el modelo procedía del Trienio; y es en la Nacional de 1871 cuando se exponen, entre otros, los Enterramientos del 3 de Mayo en la Moncloa de Vicente Palmaroli, premiado con primera medalla, a los que seguirán varios más en los años siguientes (Demange, 2004, 100-127). 
1. Antonio Solá, Monumento a Daoíz y Velarde (1830). Madrid.

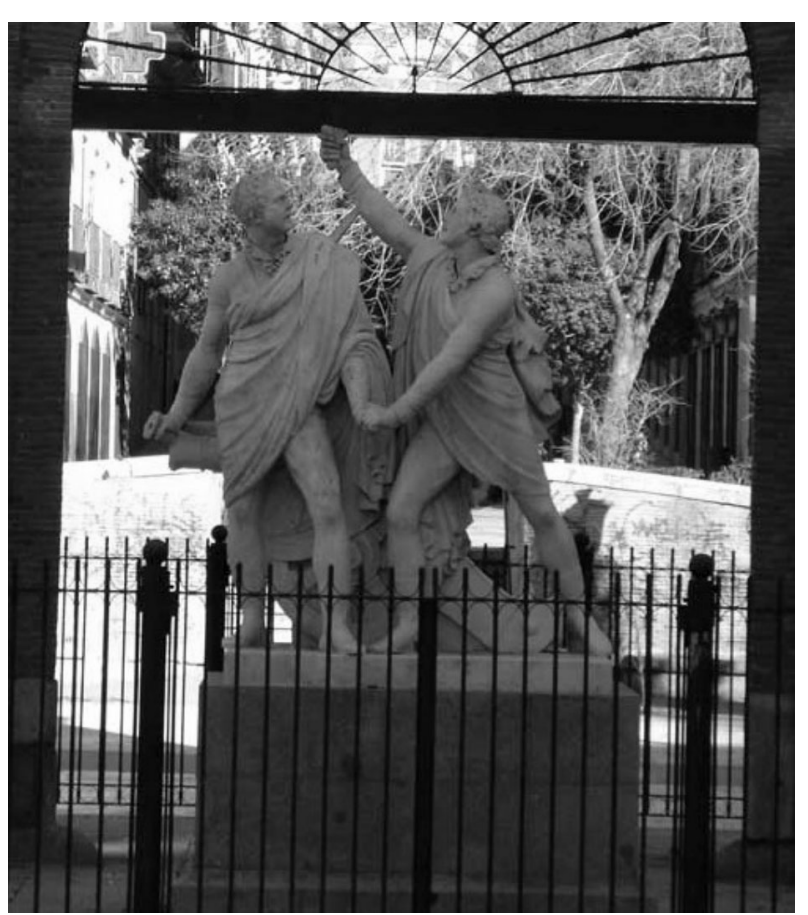

De cuantos personajes históricos fueron utilizados por el imaginario liberal como mártires anunciadores de su causa, los más importantes fueron los Comuneros. Como se ha dicho, su invención "se corresponde típicamente con el intento liberal de crear una identidad nacional congruente con los principios políticos de la sociedad liberal" (Rivero, 2005, 151). Sus enemigos lo sabían desde los primeros tiempos: los absolutistas que festejaron la entrada del Duque de Angulema en Burgos en 1823, ya entonaron ¡Viva Carlos V! y iAbajo los Comuneros! como armas ideológicas de un combate. Pero aunque, durante la primera mitad del siglo XIX, no faltaron grabados con la efigie de los ajusticiados en Villalar, no fue hasta la segunda mitad cuando sirvieron de motivo pictórico. Los Comuneros Padilla, Bravo y Maldonado en el patíbulo, de Antonio Gisbert, primera medalla en la Exposición Nacional de 1860 y adquirido por el Congreso de los Diputados, se convirtió desde el mismo momento en que se dio a conocer, en un emblema de la causa. Durante la Restauración seguirán otros, cuando los herederos de aquella ideología ya habían ocupado el poder. Reivindicar a los Comuneros en 1823 no es lo mismo que en 1881, cuando, por ejemplo, Vicente Borrás expone, en la Nacional de aquel año, Doña María de Padilla después de la derrota de Villalar.

También están ligados al imaginario liberal los temas relacionados con Antonio Pérez, refugiado en Aragón, donde el Justicia Juan de Lanuza acabaria también en el cadalso, por orden de Felipe II. Como en el caso anterior, cuadros y monumentos no llegarian a realizarse hasta la segunda mitad del XIX. Por supuesto, todas las representaciones que ilustran la leyenda negra sobre Felipe II, con cuadros como La Muerte del Príncipe don Carlos (1858) de Gisbert o El príncipe don Carlos y el duque de Alba (1881), de José Uría, entre otros, hay que vincularlos a la historiografía del liberalismo.

Además están los "mártires modernos", perfectamente comparables con los antiguos en un discurso de continuidad histórica. Los más populares fueron Mariana Pineda (cuadros de Isidoro Lozano y Juan Antonio Vera, además del monumento de Granada) y, sobre todo, aunque mucho más tarde, Torrijos. La pintura que representa el Fusilamiento de Torrijos en las playas de Málaga, de Gisbert (fig. 2), encargado directamente por Sagasta, se convirtió, desde el mismo momento de su ejecución en 1888, en el testimonio inequivoco de que los liberales habian alcanzado, al fin, la gloria: impolutos y con imperturbable dignidad, en ellos se reconoce definitivamente la razón de la historia. Ya no hay ningún riesgo en festejarla.

Hay artistas cuya ideología les lleva a tratar temas que son de una clara ideología liberal, lo que marca su trayectoria crítica. El arte no está por encima del bien y del mal. Además de Gisbert, hay que destacar a Francesc Sans, autor de Libertad e Independencia. Cádiz 1812 (1860), donde, de todos modos, opta por "una visión continuista y no revolucionaria de los sucesos gaditanos" (Pérez Vejo, 2007, 183); o Víctor Manzano: si en Los Reyes Católicos administrando justicia, segunda medalla en la Exposición Nacional de 1860, reivindica, como dijo un crítico de la época, "la monarquía democrática" (Reyero, 1987, 229), en Cisneros y los grandes, que obtuvo la misma recompensa en 1864 , ridiculiza las pretensiones de los aristócratas por intrigar, frente a Cisneros, a quien se presenta como alguien que gobierna en nombre del pueblo.

No hay que confundir el victimismo que, como estrategia persuasiva, emplean los liberales, incluso cuando el afianzamiento del régimen político de la Restauración podría 
2. Antonio Gisbert Pérez, Fusilamiento de Torrijos y sus compañeros en las playas de Málaga, 1888. Óleo sobre lienzo, $390 \times 600 \mathrm{cms}$. Museo del Prado, Madrid.

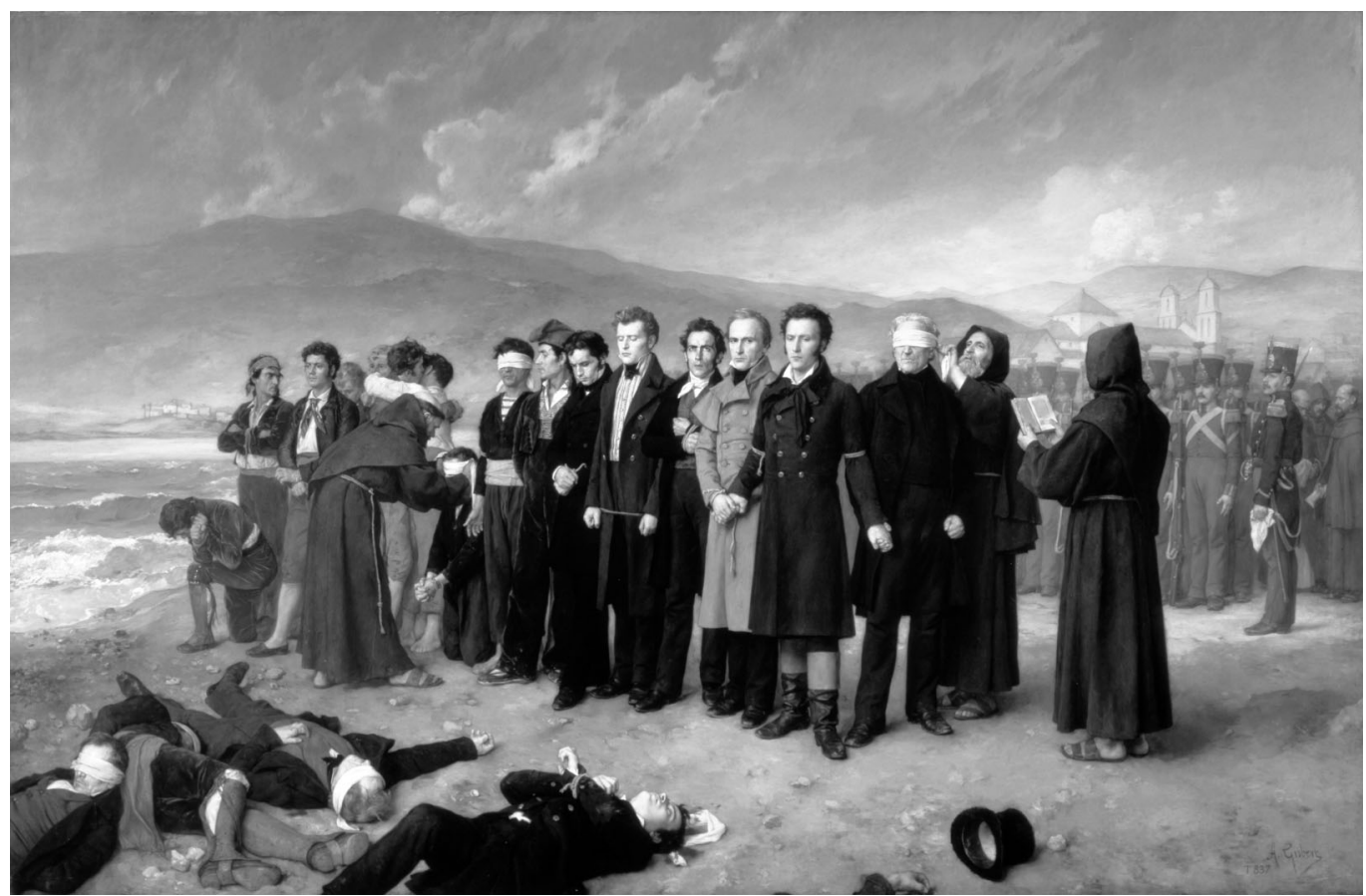

haber obviado esa dimensión, con el pesimismo esencialista que manifiestan muchos intelectuales, sobre todo a partir del último tercio del siglo XIX (Álvarez Junco, 2001; Fuentes, 2002, 13-15). Por otra parte, en relación con esa visión crítica y no complaciente del "ser español", también hay que hacer constar que fue entonces cuando triunfaron algunos temas que exploraban los "puntos oscuros" de la historia de España, como la expulsión de judíos: Vicente Cutanda obtiene una tercera medalla en 1887 por La Matanza de judíos en la Edad Media; y Emilio Sala primera medalla en 1890 por La Expulsión de los judíos de España. Son los últimos ecos de la utilización de la historia como azuzadora de conciencias (Reyero, 2005a).

\section{LA MONARQUÍA ISABELINA Y EL DISCURSO DE LA CONCILIACIÓN}

El discurso histórico conservador se sustenta fundamentalmente sobre la Monarquía. Si la adhesión al monarca es lo que distingue al Antiguo Régimen como signo de identidad de los habitantes de un territorio, frente a la conciencia popular en un destino común, como preconiza el liberalismo nacionalista, la conversión de los reyes en símbolos principales de la nación constituye una fórmula sincrética que, en virtud de su capacidad de conciliación, alcanzaría gran fortuna, puesta en marcha ya con Fernando VII durante la Guerra de la Independencia. En ese sentido, no hay solución de continuidad entre la propaganda regia institucional del Antiguo Régimen y la defensa de Isabel II como legítima heredera del trono de sus antepasados, que la historia presenta como los principales engrandecedores de la patria. Bien se sabe, no obstante, que esa legitimación - de la Monarquía parlamentaria, en general, frente a otras formas de gobierno, y de Isabel II, en particular, dada la amenaza carlista- estaba impregnada de intereses políticos muy concretos.

Hay que tener en cuenta, además, que "la identidad nacional española [...] se ha confundido con la propia historia del Estado y se ha concebido como un proyecto histórico de unidad cuya teleología ha estado en manos de monarcas y 
estadistas, al menos desde la Edad Media" (Pérez Garzón, 2005, 699-700). En ese sentido, no parece una coincidencia que algunos de los cuadros de historia que más éxito tuvieron en las primeras exposiciones nacionales, fueran protagonizados por los reyes, como anticipadores preclaros de la nación. Por citar tres pinturas significativas, Don Pelayo en Covadonga, de Luis de Madrazo, primera medalla en 1856; Los Reyes Católicos recibiendo a los cautivos cristianos en la conquista de Málaga, de Eduardo Cano de la Peña, consideración de primera medalla en 1867; y, sobre todo Doña Isabel la Católica dictando su testamento, de Eduardo Rosales, primera medalla en 1864, que hizo que su autor fuera acusado de "pintor isabelino", hasta que el tiempo terminara por diluir los intereses políticos de tan excelente pintura. El reinado de Reyes Católicos -muy en particular buscando el protagonismo de Isabel de Castilla- constituyó el período preferido de los pintores de historia (Pérez Vejo, 2005, 1131).

Entre los personajes de la historia de España cuya imagen más se repitió se encuentra Cristóbal Colón. Son varios los cuadros pintados durante el reinado de Isabel II en los que aparece como protagonista el Almirante, siempre al servicio de la Corona española. Destacan dos que alcanzarian una fortuna iconográfica extraordinaria, que desdibujaria su origen, y hasta su existencia física. Se trata del Cristóbal Colón en el convento de la Rábida, de Eduardo Cano de la Peña, primera medalla en 1856, y del Primer desembarco de Cristóbal Colón en América, de Dióscoro de la Puebla (fig. 3), primera medalla en 1862. Ambas imágenes funcionarian durante décadas como verdaderas representaciones de los sucesos a los que daban forma, cuando, en realidad, han de entenderse en el marco del grandilocuente imperialismo isabelino.

La complacencia en la victoria constituye uno de los elementos más característicos de los asuntos tratados por los pintores de historia en aquel momento, frente al pesimismo de los progresistas, que habría de desarrollarse más tarde. Episodios victoriosos respesentan, por ejemplo, los cuadros del conservador José Casado del Alisal, uno de los grandes artistas del momento, que obtuvo una de las

3. Dióscoro de la Puebla, Primer desembarco de Cristóbal Colón en América, 1862. Óleo sobre lienzo, $330 \times 545$ cms. Museo del Prado, Madrid.

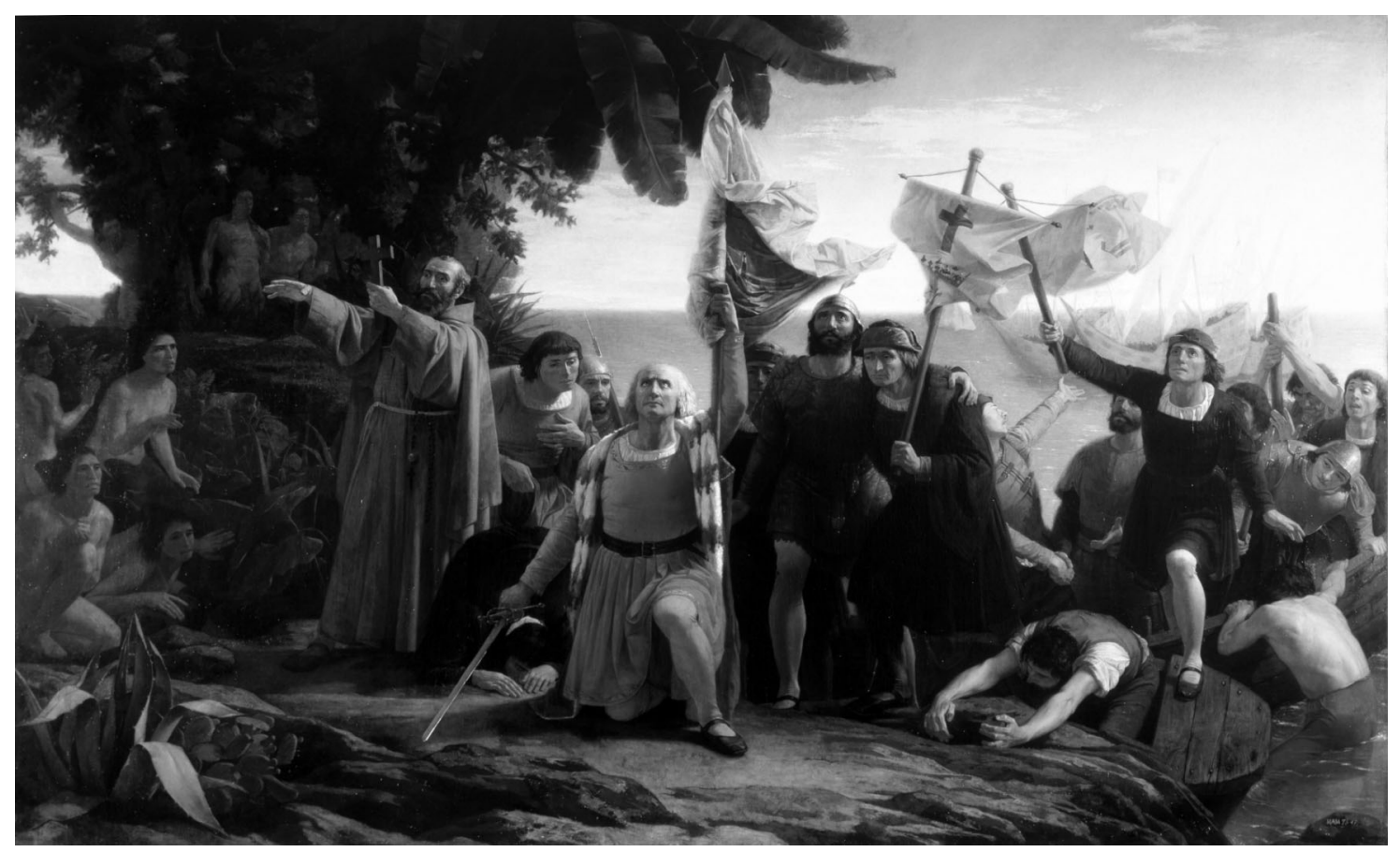


primeras medallas en 1864, con La Rendición de Bailén, y consideración de primera medalla en 1867, con Los dos caudillos, que hace referencia a la batalla de Ceriñola, donde el Gran Capitán se impuso al duque de Nemours.

La monarquía de Isabel II aspiró a convertirse en un sistema de gobierno estable, donde las fuerzas políticas parlamentarias tenían su voz en el Congreso de los Diputados. Uno de los muchos testimonios de las aspiraciones conciliadoras de aquel momento es el hecho de que, en 1863, para la decoración del hemiciclo de dicho Congreso fuesen elegidos dos pintores cuyas ideologías representaban las grandes fuerzas políticas del momento, Casado del Alisal, por los conservadores, que pintaría El juramento de las Cortes de Cádiz en 1810 (fig. 4), y Gisbert, por los liberales, que abordaría la Jura de Fernando IV en las Cortes de Valladolid, presidida por su madre María de Molina. La importancia de esta figura histórica entre los liberales tenía su tradición: recuérdese que ya en 1838 Antonio María Esquivel, que había participado en la defensa de Cádiz en 1823, había expuesto en el Liceo Artístico de Madrid Doña María de Molina amparando al Infante don
Juan, adquirido por el Conde de Toreno y que mereció un artículo de Juan Nicasio Gallego en El Liceo (Guerrero Lovillo, 1957, 18).

Por supuesto, este discurso conciliador se sustenta sobre la misma historia, ecléctica por antonomasia, sin que la concesión parezca nada del otro mundo. Pero conviene ponerlo de relieve porque reaparece en la retórica política de la Restauración. Cuando Emilio Castelar defiende que el Congreso adquiera La Campana de Huesca de Casado del Alisal dice que su propuesta no es "asunto de partido, sino deseo de todas las fracciones de la cámara [...] como todo atañe al esplendor y a la gloria de nuestra patria, es una cuestión eminentemente política y eminentemente nacional"; y recuerda que fueron unas Cortes conservadoras quienes adquirieron Doña Juana la Loca de Pradilla, por lo que es "indispensable que estas Cortes demuestren cómo tienen grandes aspiraciones cual las Cortes Conservadoras" (Reyero, 1986, 101). Lo más curioso es que los cuadros de Casado y Pradilla, que se encuentran entre los más admirados del género, apenas encierran contenidos de tipo político: la gloria nacional es la gloria del mérito artístico.

4. José Casado del Alisal, El juramento de las Cortes de Cádiz en 1810. Óleo sobre lienzo, $313 \times 379$ cms. Congreso de los Diputados, Madrid.

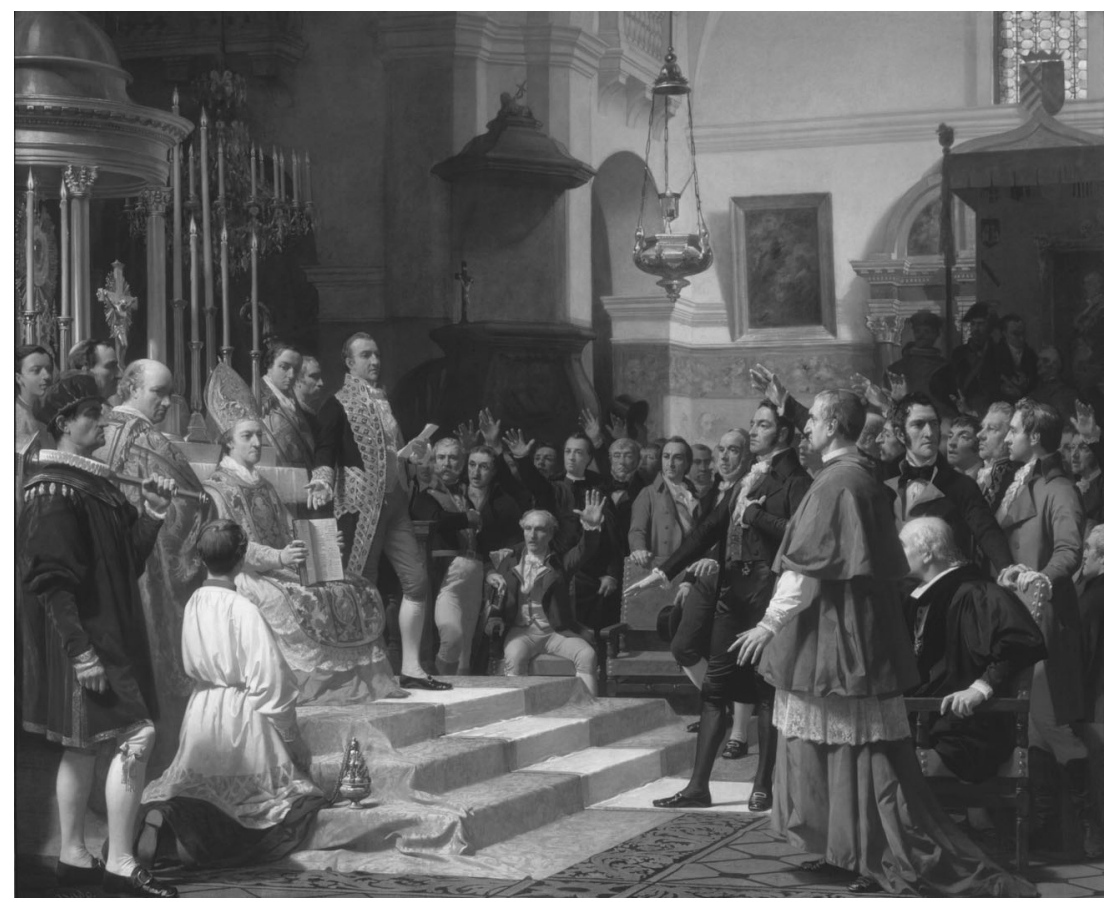


Por entonces, los argumentos políticos en la pintura ya no resultan tan necesarios.

\section{UNIDAD Y PLURALIDAD NACIONAL: EL SISTEMA DE LAS ARTES Y LA NECESIDAD DE LA HISTORIA}

A mediados del siglo XIX, el sistema de las artes está organizado de tal manera que todo favorece la práctica del género histórico: los métodos de enseñanza, los concursos para promocionarse en el extranjero, los premios de las exposiciones nacionales e internacionales, la crítica, las adquisiciones del Estado, los encargos públicos y, ante todo, la propia idea ilustrada de la obra de arte como ejercicio de contemplación edificante, sustentada en valores eruditos (Reyero, 1989, 15-50). Naturalmente todo ello es fruto de la alta consideración que la sociedad otorga al arte, en tanto que manifestación elevada del espiritu humano, y de la dependencia que los artistas tienen de las instituciones para ejercer su actividad. El arte no hubiera servido al nacionalismo, ni la política nacionalista hubiera iluminado al arte, si el sistema se hubiera configurado de otro modo.

Por eso conviene tener presentes las consecuencias de este sistema mientras mantuvo su vigencia. Dominar la pintura significaba, ante todo, saber componer elementos -figuras, objetos, paisaje, arquitectura- en una superficie plana, a través de los cuales fuese posible sugerir la existencia de un relato. No es de extrañar, pues, que la historia, sacralizada por la cultura política, fuese la fuente preferente de la que extraer asuntos. Tendemos siempre a presuponer que la erudición constituye un cierto grado de valor por sí misma. El mérito estético exige la formación de un gusto. Pero, en este campo, era una cuestión añadida.

De todos los mecanismos que componen el sistema del arte, hay dos especialmente importantes para valorar el alcance y el significado del género histórico. Éstos son los concursos y las exposiciones. Los concursos parten del principio de que una obra de arte puede ser juzgada jerárquicamente en relación con otras, y, sobre todo, que un jurado cualificado tiene capacidad para decidir el cumplimiento ideal de aquello que se propone representar, un tema, que, la mayoría de las veces, procede de la historia de España. Los artistas se adiestran, a lo largo de su formación, en el dominio de este modelo. Deben ponerlo en práctica para conseguir la ansiada pensión en el extranjero -en Roma, preferentemente- $y$, una vez alli, se preparan durante tres o cuatro años para hacer el gran cuadro de historia con el que pretenden consagrarse. Algunos insisten varias veces después, ya al margen de reglamento alguno, aunque pintar cuadros de historia, que suelen tener un gran tamaño, es tarea que requiere tiempo y esfuerzo. Hay que documentarse concienzudamente, saber elegir un tema atractivo y que no haya sido visto, porque los temas tratados que tienen éxito entran enseguida a formar parte de un museo imaginario que tiende a excluir a quienes intentan emularlos.

La importancia de las exposiciones como germen de la conversión de la práctica artística en un fenómeno de masas es incuestionable (Gutiérrez Burón, 1987). Los reglamentos por los que se rigieron favorecieron la práctica del género histórico, pero también los premios concedidos y el mercado del arte, mayoritariamente en manos del Estado. También, por supuesto, la crítica, eminentemente minuciosa y literaria, se complacía en describir una y otra vez los asuntos representados y su moraleja, con todo lujo de detalles sobre personajes, caracteres, anécdotas y circunstancias. Es mucho más difícil extenderse hablando sobre un paisaje o sobre una naturaleza muerta, que sobre un cuadro de historia, salvo que el autor tenga un criterio estético muy formado y se dirija a profesionales especializados, lo que no siempre sucedía en el siglo XIX, donde el destinatario era público heterogéneo, ávido de conocimientos y de opiniones, que no siempre había contemplado -muchas veces ni siquiera llegaría a contemplar- las obras directamente. En ese sentido, en el proceso de conversión de los cuadros de historia en imágenes, tuvieron un papel crucial los avances en la reproducción, que llenarian las revistas ilustradas de escenas históricas, mucho más vistosas y lucidas, que un paisaje de Modest Urgell o de Aureliano de Beruete, cuya sutileza era entonces irreproducible.

Tanto la actividad formativa como los concursos y las exposiciones proyectan las obras sobre un ámbito espacial que puede ser local, regional, nacional o internacional. El significado de un cuadro -y muy especialmente si es histórico- no es el mismo según ese ámbito espacial en el que se percibe y difunde. Incluso puede darse el caso de que la dimensión nacionalista que encierre una misma pieza quede modificada al ser exhibida en otro lugar. Dada la particular articulación nacional de España, donde el peso de las 
tradiciones artísticas de algunos centros -como Sevilla, por ejemplo- y la creciente importancia de otros -Barcelona y Valencia, principalmente, pero también Zaragoza, Málaga, Valladolid, Murcia o Bilbao- es tan grande, el alcance de una pintura histórica está sometido a factores externos que merecen ser tenidos en cuenta.

Es evidente, por ejemplo, que obras como El Origen del escudo del condado de Barcelona de Claudi Lorenzale, en cuya elección del tema intervinieron los hermanos Manuel y Pau Milà i Fontanals (Fontbona-Jorba, 1999, 199), entre otros, ilustra una identidad catalana. Algunos de esos temas nunca se presentaron en Madrid, y, por lo tanto, no formaron nunca parte de un orgullo nacional "español". Pero hubo otros muchos pintores catalanes que acudieron a las Nacionales madrileñas con temas de la historia propia, sobre todo de la Edad Media, como Manuel Ferrán - Antoni Caba, que fueron perfectamente entendidos y asumidos en un marco común. Otros catalanes, como Sans - Martí Alsina, abordaron temas típicamente españoles, como Trafalgar o Numancia. También hay figuras históricas, como el Príncipe de Viana, por ejemplo, que simultáneamente sirvieron para identificar una y otra sensibilidad, según las piezas y su lugar de exhibición. Incluso hay héroes muy españoles que llegan a estar muy catalanizados, como Colón, por ejemplo: siempre es en Barcelona donde es recibido por los Reyes Católicos.

En Valencia hubo una sistemática promoción del género histórico, en el que se formaron algunos de los más importantes pintores españoles del fin de siglo, como Sorolla o Pinazo (Gracia, 1987). Como en otros lugares, se promovió la representación de temas locales, la mayoría de los cuales no alcanzaron una proyección nacional. Pero se da el caso, por ejemplo, de que Ignacio Pinazo, que pinta en Roma, como último envío de la pensión concedida por la Diputación de Valencia, los Últimos momentos del rey don Jaime el Conquistador, un héroe valenciano por excelencia, realiza una réplica, en mayor tamaño, para presentarlo a la Exposición Nacional de Madrid de 1881, donde, naturalmente, fue visto como un tema de la historia de España.

Todos los pintores formados en los diversos centros artísticos que entonces había en España, los mejores de los cuales continuaron su preparación en el extranjero, abordaron temas locales, dando como resultado un gran repertorio, como por ejemplo en Zaragoza (Lorente, 1996). Otros procuraron inspirarse en personajes que, sin perder la vinculación con una ciudad concreta, fuesen vistos como nacionales: es el caso, por ejemplo, de San Fernando, que inspira al sevillano Virgilio Mattoni Las Postrimerías de Fernando III el Santo, segunda medalla en la Nacional de 1887.

En centros artísticos todavía muy secundarios en el siglo XIX, como el País Vasco, por ejemplo, que, sin embargo, llegarían a alcanzar una importancia enorme a partir del cambio de siglo, también hay ya testimonios de la práctica del genéro histórico con intereses locales. Mamerto Seguí, por ejemplo, pinta en 1882 El árbol malato, donde el mítico Jaun Zuría señala el punto hasta el cual fue perseguido el rey de León (González de Durana, 1992, 428).

\section{EL TRIUNFO DEL ESTADO-NACIÓN Y LA CRISIS DEL MODELO HISTORICISTA}

Suele decirse que la pintura de historia que se desarrolla durante los primeros quince años de la Restauración, entre 1876 y 1892 aproximadamente, antes de la defintiva desacreditación del género, resulta menos grandilocuente en sus temas, sus héroes se hacen más humanos y participan en acontecimientos menos relevantes políticamente, aunque están concebidos de una forma tanto o más grandiosa y espectacular. Es cierto que esta llamada "segunda generación" se ha formado en ideales estéticos, fundamentados en el realismo -es decir la pintura como resultado de una experiencia sensorial- que están reñidos con la idea de reconstrucción de un asunto del pasado nunca visto. También -no hay que olvidarlo- estos pintores son más cosmopolitas y aspiran a un éxito mundano, donde los temas han de llamar indistintamente la atención a un público nacional o internacional de forma inmediata, por lo que la truculencia o emotividad de los asuntos constituye un elemento narrativo más eficiente que el tradicional discurso épico del nacionalismo ortodoxo.

Es así como triunfa, en primer lugar, Francisco Pradilla con su cuadro Doña Juana la Loca, medalla de Honor en 1878, realizado en Roma al amparo de la recién creada Academia Española de Bellas Artes, que será uno de los puntales del género durante los primeros años de su andadura. De allí saldrán, en los años sucesivos, entre otros, Antonio Muñoz 
Degrain y José Moreno Carbonero, primeras medallas en 1884 por Los Amantes de Teruel y La conversión del Duque de Gandía. Los tres cuadros representan temas nacionales, desde luego, pero en su dimensión emotiva se convierten en universales. No puede decirse que defiendan tal o cual opción política, como había sido más habitual hasta entonces.

El servicio que prestan a la identidad nacional sigue presente, naturalmente, pero se plantea ya en otros términos, en tanto que tipos y episodios que supuestamente sólo pueden darse en España; o, más bien, en tanto que han sido concebidos por españoles que han merecido un reconomiento internacional. En tal sentido, las exposiciones universales aparecen en el horizonte del pintor de historia -y del nacionalismo español- como un destino cada vez más merecedor de ser tenido en cuenta. Cuadros de historia ya habian sido enviados a las exposiciones universales durante la época isabelina (en la de París de 1867 triunfó Doña Isabel la Católica dictando su testamento, de Rosales), pero fue a partir de los años setenta y ochenta cuando se llevó a una política sistemática de promoción del arte español en Europa y América, en el marco de la cual los cuadros de historia desempeñaron un gran papel. Fue precisamente el fracaso que supuso la fabulosa sucesión de cuadros de historia desplegados en la Exposición Universal de París de 1889, lo que aceleró la crisis del género, a favor de los temas de carácter realista y social, que, en la última década del siglo, terminaron por desplazar a los de historia.

De todos modos, es cierto que la hegemonía de la pintura de historia como género coincide con el triunfo del estadonación (Pérez Vejo, 2001; Pérez Vejo, 2005, 1121). Curiosamente es también entonces cuando empieza a diluirse el sentido edificante de sus argumentos, no digamos ya su sentido reivindicativo, casi de compromiso político, que, al menos en el enunciado de los temas, había tenido en los origenes del liberalismo. Con todo, las instituciones del Estado siguen encargando cuadros de historia en el último cuarto del siglo XIX, aunque a veces da la impresión de que los artistas colaboran ya con ese mecenazgo a contrapelo de las verdaderas preocupaciones que dominan la creación plástica, donde la historia ha dejado de suscitar las mismas motivaciones que antaño.

En ese sentido, el mejor testimonio de la apoteosis de la pintura de historia, al servicio de los ideales nacionalistas del Estado, verdadero cénit que precede al ocaso, es la decoración de la Sala de Conferencia del Palacio del Senado, hoy Salón de Pasos Perdidos, promovida entre 1881 y 1888 por el entonces presidente, el marqués de Barzanallana. Alli se colocaron La Rendición de Granada de Francisco Pradilla, la Entrada de Roger de Flor en Constantinopla de José Moreno Carbonero, La Conversión de Recaredo de Antonio Muñoz Degrain (hoy sustuida por La muerte del marqués del Duero de Joaquín Agrasot) y la Jura de la Constitución por Maria Cristina de Habsburgo y Lorena, tras su conclusión en 1897, obra de Francisco Jover y Joaquín Sorolla (aunque originariamente estaba previsto colocar el Combate Naval de Lepanto de Juan Luna y Novicio). De haberse mantenido el programa iconográfico original, nos encontraríamos con el más significativo conjunto del nacionalismo español, ya que la sala se completa con esculturas de Cisneros, por Carlos Nicoli, Colón, por Juan Sanmartín, Juan de Austria, por Elías Martín, y Hernán Cortés, por Agapito Vallmitjana. En los programas decorativos de otras instituciones, como el Paraninfo de la Universidad de Barcelona, o de algunas diputaciones provinciales, como la de Zamora, sobrevive esa misma retórica nacionalista que en esos años las exposiciones artísticas ya casi habian abandonado.

\section{¿POR QUÉ LA HISTORIA SOBREVIVE EN LOS MONUMENTOS?}

La Edad de Oro del monumento público coincide con la Restauración y alcanza su mayor prestigio como actividad artística en torno al cambio de siglo (Reyero, 1999; Peiró, 2004). Por entonces la pintura de historia, cumplida la función identitaria que había desempeñado, ya está completamente desacreditada entre artistas, críticos y público. Pero asuntos y personajes del pasado no desaparecen por completo de la inspiración artística en torno a 1900, en virtud de esta tipología en auge, aunque quedan restringidos preferentemente a ella, con independencia del uso que las imágenes históricas, en distintos soportes, siguen teniendo todavía. Esta es una cuestión que sólo resulta sorprendente cuando se desconoce el papel que pintura y escultura tenían en la sociedad de su tiempo, que hay que relacionar, a su vez, con la forma, bien diferente, en la que pintores y escultores ejercian su actividad. Aquéllos alcanzan antes su autonomía, tienden a pintar rápidamente 
cuadros pequeños de cualquier tema que se pone ante sus ojos, mientras los escultores siguen enfrentándose a una tarea laboriosa y compleja, en la que intervienen muchos factores externos a ellos.

Antes de 1875 se habían Ilevado a cabo algunos monumentos cuyo sentido nacionalista es evidente. El caso más importante es el dedicado a Cervantes, de Antonio Solá, en 1835, colocado frente al Congreso de los Diputados en Madrid: significativamente, todos los grabados que tratan de dar a conocer el edificio, al que entonces se concede una gran importancia representativa, incluyen la figura del héroe de Lepanto y autor del Quijote, que es uno de los héroes españoles por excelencia. Otro monumento importante, en parecido sentido, es el dedicado a Murillo, en la plaza del Museo, en Sevilla, inaugurado en 1864, cuyo modelo se utilizaría más tarde para el de Madrid, inaugurado por Amadeo de Saboya en 1871. De ese momento (1868-69) es también el dedicado a Fray Luis de León en Salamanca. Como se ve, para los primeros monumentos nacionalistas se eligen figuras en las que puede generarse una identificación unánime, sin enemigos ni imposiciones: solamente el orgullo de compatriotas. Es bien significativo que escritores y pintores se encuentren entre los primeros españoles elevados a los pedestales. No obstante, no hay que perder de vista su significado en relación con la ciudad donde se encuentran. En general, escritores y artistas sirvieron al nacionalismo y al orgullo local indistintamente, como prueban los casos de Bécquer (1910-12) en Sevilla o de Pereda (1911) en Santander, ambos obra de CoullautValera.

Es cierto que, ya en época isabelina, algunos tuvieron un carácter de marcada facción política, como el de Mendizábal (1854-69), en Madrid, cuyas controversias Ilegaron hasta la época de Franco, cuando se sustituyó por el más piadoso de Tirso de Molina, en la plaza rebautizada con su nombre, que perdió el del Progreso; o los dedicados a la reina Isabel II, todos los cuales cayeron en 1868. Esa vertiente política, que en general tiene toda figura pública contemporánea, constituye un elemento fundamental de la escultura pública.

Madrid, como capital de España, fue el privilegiado escenario para el despligue de contenidos nacionalistas. Además de los ya mencionados, relacionados con los episodios del Dos de Mayo, algunos de los que más explícitamente contribuyen a exaltar nacionalismo español, de un modo similar a como antes lo había hecho la pintura de historia, son el de Isabel Católica (1881-83), de Manuel Oms; el de Cristóbal Colón (1880-1892), de Arturo Mélida y Jeroni Suñol; y, sobre todo, el de Alfonso XII (1902-1922), en el Parque del Retiro, verdadero "altar de la patria" que constituye un espectacular despliegue en mármol y bronce de las más profundas aspiraciones del régimen político de la Restauración.

No obstante, también algunos de los emplazados en otras ciudades han de entenderse en clave nacionalista, sobre todo si su promoción, financiación y difusión se produjo en un ámbito nacional. En este caso, su ubicación en una ciudad concreta, por justificadas razones históricas, no desdibuja sus más amplias miras. Es el caso, por ejemplo, del Monumento a Isabel la Católica (1892) en Granada, obra de Benlliure (fig. 5); el de Colón (1905) en Valladolid, de Antonio Susillo; o el dedicado a Las Cortes y Sitio de Cádiz (1912-1929), de Aniceto Marinas y Modesto López Otero, en esta ciudad. Por supuesto también los varios que se levantaron en relación con héroes o gestas de la guerra de la Independencia en Gerona, Madrid, Pontevedra, Santander, Segovia, Sevilla, Tarragona, Vitoria o Zaragoza. El de Colón en Barcelona, ideado en 1882 e inaugurado en 1887, como emblema de la Exposición Internacional del año siguiente, es muy ilustrativo del papel que se quiere otorgar a la Corona de Aragón, y en particular a Cataluña, en la empresa americana, en general monopolizada desde el punto conmemorativo por Castilla.

Sin embargo, la mayoría de los monumentos levantados en las ciudades españolas entre las décadas finales del siglo XIX y las primeras del XX, honran el pasado y los héroes locales, con independencia de su papel en un ámbito más amplio. Muy evidente resulta, entre otros muchos, en el Monumento al Padre Feijoo (1887) en Orense, de Juan Soler; el del Padre Mariana (1888) en Talavera de la Reina, de Eugenio Duque; el de Jovellanos (1891) en Gijón, de Manuel Fuxá; o el del Padre Flórez (1906) en Villadiego, de Aniceto Marinas. No puede decirse que ninguno de ellos aliente el orgullo nacional español.

Incluso cuando se trata de grandes personajes históricos, su presencia en una determinada ciudad se debe más a una vinculación más o menos circunstancial con ella, que a la empresa que les hizo famosos: es el caso, por ejemplo, del 
5. Mariano Benlliure, Monumento a Isabel la Católica (1892). Granada.

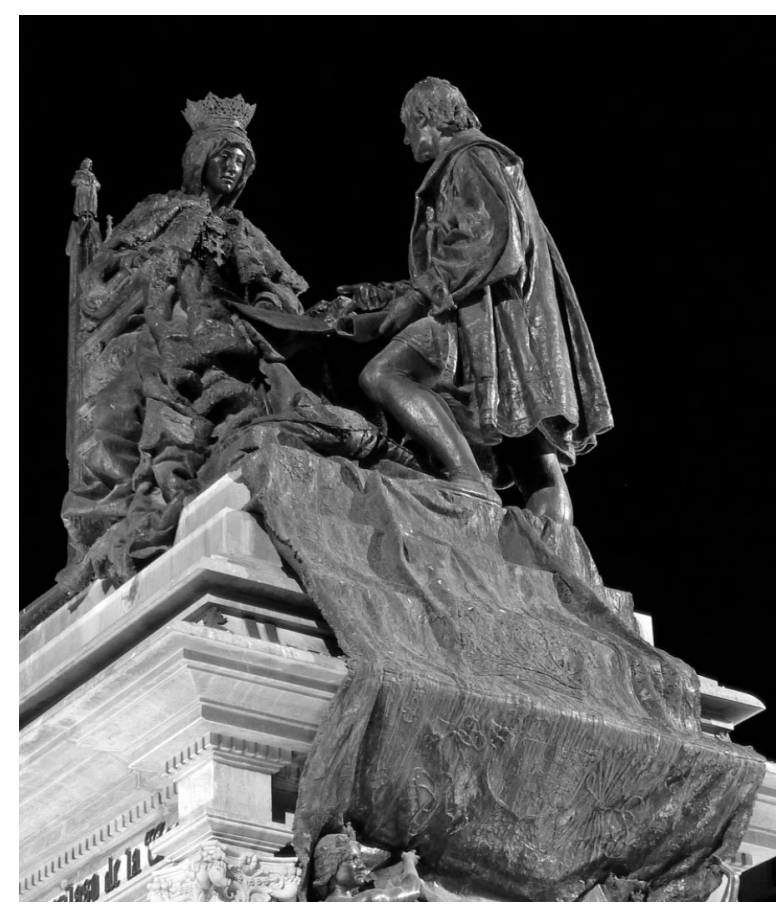

Monumento a Colón en Las Palmas de Gran Canaria, por donde el Almirante pasó antes de salir hacia América, o el de Isabel la Católica en Medina del Campo, donde nació la reina. Todo ello viene a demostrar que el monumento tiene un papel socializador muy grande, pero más bien restringido al orgullo local. De hecho, no todos los monumentos en España funcionaron como instrumentos propagandísticos del estado-nación.

Ésa constituye una de las principales razones por las cuales los monumentos conmemorativos en los que aparecían personajes históricos sobrevivieron a la crítica que, sobre la instrumentalización del pasado nacional, hicieron las generacioens de intelectuales más críticos, a partir de los años finales del siglo XIX. Tendió a darse por supuesto que el orgullo local encerraba una dosis de autenticidad que en el nacionalismo de estado parecía impostada.

Hay que tener en cuenta, además, que, a diferencia de los cuadros, que se convierten fácilmente en imágenes, susceptibles de ser difundidas como iconos, al margen de la existencia de un objeto en un lugar, que, incluso, llega a olvidarse, las esculturas en el espacio público conservan la dimensión circunstancial en la que están ubicadas, donde lo propiamente representativo se desdibuja, por lo que fácilmente adquieren otras significaciones, más abstractas 0 , incluso, más subjetivas, derivadas de una pura percepción física, que no exige una mirada precisa ni una narración exhaustiva, como la pintura, ante la que hay que colocarse intencionadamente para ver $\mathrm{y}$ entender.

Tampoco hay que olvidar que, en general, el monumento conmemorativo, como tipología, tiene un desarrollo más lento que un cuadro. Pero no por una falta de concienciación sobre la necesidad de que exista -los discursos académicos y los críticos reclaman y proponen constantemente el levantamiento de monumentos- sino por razones prácticas, ya que la construcción de un monumento es un proceso más caro y dificultoso que pintar un cuadro. Exige tener en cuenta a muchas personas y superar inciertos avatares. De hecho, muchísimos de los proyectos que se plantearon se quedaron en el camino.

El hecho de que un monumento sea un ejercicio público de poder, frente a la pintura, cuyos temas terminan por estar exclusivamente en manos de su creador, facilitó que los discursos históricos continuaran vigentes en la escultura por más tiempo. Al fin y al cabo, las clases dominantes, educadas en unos ideales antiguos, estaban deseando ejercer ese poder, llevar a cabo, finalmente, aquella idea surgida años atrás que otros no habían sido capaces de coronar. En ese sentido, la escultura pública es una manifestación artística que aún necesita más que la pintura del amparo oficial, incluso de una cierta unanimidad ideológica para funcionar como icono identitario. Sólo las figuras consagradas por la historia disfrutan de ese asentimiento.

En los monumentos se reconoce un personaje, no un asunto, y la validez del personaje está por encima del modo de relatar. Lo que verdaderamente entró en crisis de la pintura fue la falta de credibilidad de la puesta en escena y la manipulación ideológica de la trama, pero los protagonistas de la historia nunca estuvieron desacreditados. Pudo haber una mayor simpatía hacia unos personajes o hacia otros, hacia los reyes o hacia los héroes populares, hacia la inusitada valentía de las mujeres 0 al viril arrojo de los hombres, hacia los benefactores o hacia los mi- 
litares, hacia los descubridores o hacia los gobernantes, pero, en tanto que seres humanos, el interés hacia su personalidad no se perdió nunca. La escultura, que siempre arrastró la limitación de no poder contar una historia con la misma facilidad de la pintura, resultó, sin embargo, una práctica muy idónea para explorar el alma individual de los protagonistas. Ese aspecto, eminentemente expresivo y simbólico, se encuentra muy incardinado en la cultura artística de 1900 .
Finalmente, la expansión del monumento público coincide con el "amueblamiento" de las ciudades, especialmente de los ensanches, necesitados de identidad histórica, pero también de los antiguos cascos históricos, que tenian que ser embellecidos porque la ciudad era ya el gran escenario de la vida moderna. Toda ciudad que se preciara debía tener monumentos. En el fondo, lo importante era que el monumento existiera. Ya se encontrarían motivos para pronunciar un discurso.

\section{BIBLIOGRAFÍA}

Checa, Fernando (1992): "Los frescos del Palacio Real Nuevo de Madrid y el fin del lenguaje alegórico", Archivo Español de Arte, 65 (n. ${ }^{\circ}$ 258), 157-178.

D. M. N. y R. y D. J. S. M. (1829): Relación de la entrada en la M.H.V. de Madrid de nuestra augusta reina y señora Doña María Cristina de Borbón, Madrid, Imprenta de D. Eusebio Arago.

De Miguel Egea, Pilar (1985): "Frescos de Juan Antonio de Ribera en el Palacio de El Pardo y en el Palacio Real de Madrid", Reales Sitios, 17-24.

Demange, Christian (2004): El Dos de Mayo. Mito y fiesta nacional (1808-1958), Madrid, Marcial Pons Historia.

Díez, José Luis (1992): La pintura de historia del siglo XIX en España, Madrid, Museo del Prado.

Fuentes, Juan Francisco (2002): "Iconografía de la idea de España en la segunda mitad del siglo XIX", Cercles, Revista d'História Cultural, 5, 8-25.

González de Durana, Javier (1992): "La invención de la pintura vasca", en el catálogo de la exposición Centro y Periferia en la modernización de la pintura española, 1880-1918, Madrid, Ministerio de Cultura, 394-439.

Gracia, Carmen (1987): Las pensiones de pintura de la Diputación de Valencia, Valencia, Instituciò Alfonso el Magnànim.
Guerrero Lovillo, José (1957): Antonio María Esquivel, Madrid, CSIC.

Gutiérrez Burón, Jesús (1987): Exposiciones Nacionales de Pintura en España en el sigloXIX, Madrid, Universidad Complutense.

Lorente Lorente, Jesús-Pedro (1996): El arte de soñar el pasado. Pinturas de historia en las colecciones zaragozanas, Zaragoza, Ayuntamiento.

Peiró Martín, Ignacio (2004): "EL tiempo de las esculturas: La construcción de la 'Cultura del Recuerdo' española durante la Restauración", en Quinto encuentro de estudios sobre el Justicia de Aragón. Zaragoza, 28 y 29 de abril de 2004, Zaragoza, Justicia de Aragón, 41-62.

Pérez Vejo, Tomás (2001): Pintura de historia e identidad nacional en España, Madrid, Universidad Complutense.

Pérez Vejo, Tomás (2005): "Imágenes, historia y nación. La construcción de un imaginario histórico en la pintura española del siglo XIX", en Francisco Colom González (ed.): Relatos de nación. La construcción de las identidades nacionales en el mundo hispano, Madrid, Iberoamericana-Vervuert, 1117-1154.

Pérez Vejo, Tomás (2007): "Debates en torno a la construcción de la memoria: la representación de las Cortes de Cádiz en la pintura de historia española decimonónica", en: Alberto Ramos Santanda (coord.), Lecturas sobre 1812, Cádiz,
Aceptado: 16 de mayo de 2008 
Ayuntamiento-Universidad, pp. 181192.

Reyero, Carlos (1986): "Castelar y la pintura de historia", Boletín de la Real Academia de la Historia, CLXXXIII, 95-107.

Reyero, Carlos (1987): Imagen histórica de España, 1850-1900, Madrid, EspasaCalpe.

Reyero, Carlos (1989): La pintura de historia en España. Esplendor un género en el siglo XIX, Madrid, Cátedra.
Reyero, Carlos (2002): "La historia pasada como historia presente. Rosales, Casado y Gisbert o la política en el Prado", en Historias inmortales, Barcelona, Galaxia Gutemberg-Círculo de Lectores, 331-351.

Reyero, Carlos (2005a): "Acogidos en conciencia. Rechazados, perdedores y víctimas en la pintura de historia del siglo XIX", en Acogidos y rechazados en la historia, Valladolid, Universidad.
Reyero, Carlos (2005b): "La ambigüedad de Clío. Pintura de historia y cambios ideológicos en la España del siglo XIX", Revista del Instituto de Investigaciones Eséticas, 87, 37-63.

Rivero, Ángel (2005): "El mito comunero y la construcción de la identidad nacional en el liberalismo español", en Francisco Colom González (ed.): Relatos de nación. La construcción de las identidades nacionales en el mundo hispano, Madrid, Iberoamericana-Vervuert, 147-158. 